\title{
Thermodynamic modeling of water vapor influence on development process of the lower- Karmalinsky bituminous deposit by the sagd method
}

\author{
Eduard Korolev' ${ }^{1}$, Anatoly Bakhtin ${ }^{1}$, Aleksey Eskin 1,*, Enza Barieva ${ }^{2}$, Rezeda \\ Gabdelvalieva $^{1}$, and Albert Korolev ${ }^{1}$ \\ ${ }^{1}$ Kazan Federal University, 420008, Russia \\ ${ }^{2}$ Kazan State Power Engineering University, 420066, Russia
}

\begin{abstract}
The development of the Lower-Karmalinsky bituminous deposit is currently made by the SAGD method. However, focusing on the reduction of bitumen viscosity, the problem of mineral phase's transformation at the reservoir due to anthropogenic impact overlooked. In this work, using thermodynamic modeling, shown that the injection of superheated steam into bitumen-saturated sandstone layer will lead to the dissolution of calcite cement.
\end{abstract}

\section{Introduction}

In recent years, in order to increase hydrocarbon reserves in the Tatarstan Republic, work is underway to optimize of bitumen deposits development [1]. One of the experimental testing sites located within the Almetyevsk region is the Lower-Karmalinsky bituminous deposit. Tectonically the deposit is confined to the western slope of the South Tatar arch. Bituminous deposit belongs to the layer-uplifted deposit type. The bitumensaturated rocks are sandstones of the Sheshminsky horizon of the Ufa low Permian tier $\left(\mathrm{P}_{1} \mathrm{ss}\right)$ with an average thickness of about $26 \mathrm{~m} \mathrm{[2].} \mathrm{The} \mathrm{reservoir} \mathrm{is} \mathrm{confined} \mathrm{to} \mathrm{the} \mathrm{Lower-}$ Karmalinskybrachianticlinal structure, which stretch in the northeast direction. Its length is about $13 \mathrm{~km}$, width - 2-3 km, height - up to $45 \mathrm{~m}$.

Currently, for development of the Lower-Karmalinsky bitumen deposit, steam assisted gravity drainage technology (SAGD) is being tested [3,4]. The SAGD technology has proven itself in the development of bituminous sandstones in Canada. The similar method of hydrocarbon extraction was applied on the Lower-Karmalinsky bitumen field. Last time for enhanced of oil recovery in reservoir used pressurization a water vapor with a temperature of $\sim 180^{\circ} \mathrm{C}$ and pressure from $0.4-0.55$ to $2.5-4.0 \mathrm{MPa}$ [5].

In the productive sandstone layer two horizontal wells are drilled one above the other. To the upper injection well is supplied water steam with a temperature of about $+180^{\circ} \mathrm{C}$, which heats the layer of bituminous sandstone. Condensing water enriches by hydrocarbons

\footnotetext{
*Corresponding author: eskin.aleksey@gmail.com
} 
and enters the producing underlying well. Thus, between the two wells, a constant circulation of the oil-water fluid is created. Over time, the heat chamber increases in size, reaching 10.0-15 m. According to the simulation, the heat-affected zone can extend over distances of 25-30 m from the injection well. The formation of intensive circulation zone within a local area can lead to illuviation not only hydrocarbons from sand reservoirs but also their mineral components. If it poorly consolidated sandstones, then it can lead to problems in their development.

The superheated water vapor injection into the bitumen deposit will drastically change the hydrogeological conditions of the reservoir, which can lead to changes of filtrationcapacity properties of sandstone at developing. Under the influence of temperature, a wide variety of chemical reactions can be activated, contributing to the dissolution and subsequent deposition of mineral phases within the sand layer. Given this, in the proposed article, thermodynamic modeling of possible hydrochemical processes was carried out with an assessment of their effect on the bituminous reservoir being developed.

\section{Object}

In thermodynamic modeling, the data of the mineral composition of sandstones and the chemical composition of interstitial waters in the bitumen reservoir are used. As shown by optical studies, the bitumen-saturated reservoir is represented by greywacke sandstones. In them, the debris components are represented by rounded fragments of mafics effusive rocks (55-60\%), subrounded metamorphic and siliceous rocks (20-25\%), subrounded quartz grains $(15 \%)$, angular fragments of plagioclase and microcline $(5 \%)$, and rare scales of muscovite and chlorite. Allothigenic fragments of minerals and rocks are cemented by claycalcite cement, which constituting $10-30 \%$ of the rock. In the productive part of the bitumen deposits there is a cement of two types: pore-filling and argillaceous lump cement. In the most bituminous part of the sandstone pack, organic-mineral cement accounts for 10$35 \%$ of the rock. The organic components are represented by medium and heavy oil, the mineral components are calcite and analcime. The sandstone reservoir porosity is not constant, varies from 10 to $30 \%$ [6].

The bituminous reservoir of the Lower-Karmalinsky field is coinciding with low yield aquifer and locally with water bearing stratum terrigenous complex of the Sheshminsky horizon of the Ufimian stage. Water-bearing rocks are porous sandstones and siltstones with a thickness of 4 to $29 \mathrm{~m}$. The underground waters of the Ufimian sediments are pressure water, piezometric levels are set above the top of aquifer layer. The magnitude of the head flow above the top of the reservoir - from 50 to $60 \mathrm{~m}$. Piezometric levels in wells are often set at absolute elevations from 75 to $80 \mathrm{~m}$. Well water output (discharge) varies from 1.4 to $150 \mathrm{~m}^{3}$ per day. The recharge of the Sheshminsky horizon is carried out by infiltration from above and ascending filtration from below. Recharge of groundwater into the bitumen deposit occurs through cracks or tectonically weakened zones. The main direction of underground water flow is westerly direction towards to the Sheshma River valley. In the cross-section of the Lower-Karmalinsky bitumen deposit there are several aquifers, which are practically unrelated. The groundwater of deposit is sodium hydrocarbonate waters with TDS (Total dissolved solids) of 1.2-5.7 g/L, containing a significant amount of hydrogen sulfide [7]. Waters of the underlying sandstones and edge waters are sulphate-calcium-magnesium and hydrocarbonate-calcium type with TDS up to $1.0 \mathrm{~g} / \mathrm{L}$. 


\section{Results}

According chemical analysis data of bitumen deposit groundwater's, which planned for development, hydrocarbonate ions are predominate in them, sulphate ion and chlorite ion are in small amount. From cations, in accordance with the hydrochemical type, sodium ions prevails (Table 1). Potassium, calcium and magnesium ions are present in insignificant amounts. TDS of the formation water varies from 1.5 to $1.9 \mathrm{~g} / \mathrm{L}, \mathrm{pH}$ corresponds to weak acid medium with the temperature $+8^{\circ} \mathrm{C}$.

Table 1.The chemical composition of groundwater Lower-Karmalinsky bitumen deposit.

\begin{tabular}{|c|c|c|c|c|c|c|c|c|c|}
\hline \multirow{2}{*}{ Sample } & \multicolumn{7}{|c|}{ The content of major elements, $\mathrm{mg} / \mathrm{L}$} & \multirow{2}{*}{$\mathrm{mg} / \mathrm{L}$} & \multirow{2}{*}{$\mathrm{pH}$} \\
\cline { 2 - 10 } & $\mathrm{Ca}^{2+}$ & $\mathrm{Mg}^{2+}$ & $\mathrm{Na}^{+}$ & $\mathrm{K}^{+}$ & $\mathrm{HCO}_{3}{ }^{-}$ & $\mathrm{SO}_{4}^{2-}$ & $\mathrm{Cl}^{-}$ & & \\
\hline 1 & 12,82 & 16,84 & 953,20 & 9,68 & 470,21 & 95,25 & 99,00 & 1657 & 6,3 \\
\hline 2 & 7,27 & 16,27 & 1097,95 & 8,17 & 620,34 & 33,08 & 92,92 & 1876 & 6,1 \\
\hline 3 & 8,51 & 24,45 & 1082,19 & 9,70 & 608,70 & 14,05 & 125,40 & 1873 & 6,2 \\
\hline 4 & 6,31 & 20,09 & 922,78 & 9,18 & 557,79 & 36,16 & 109,69 & 1662 & 6,3 \\
\hline 5 & 9,23 & 22,47 & 855,29 & 13,88 & 411,15 & 146,89 & 104,09 & 1563 & 6,5 \\
\hline
\end{tabular}

Given the temperature difference between stratal and injected waters is necessary to consider how increasing temperature in the bituminous reservoir will affect on the changes of groundwater chemical composition and their interaction with matrix minerals. Analysis of bituminous sandstone mineral composition showed that the most unstable phase will be calcite cement. Therefore, in this work we carried out a thermodynamic simulation of calcite interaction process with waters having different temperatures. Since the initial process water injected into the layer of bitumen-saturated sandstone has a temperature of $+180^{\circ} \mathrm{C}$, all calculations were carried out in the temperature range of $25-200^{\circ} \mathrm{C}$. To calculate the temperature dependence of the Gibbs energy change, we used the carbonate equilibrium equation:

$$
\mathrm{CaCO}_{3}+\mathrm{H}_{2} \mathrm{O}+\mathrm{CO}_{2}=\mathrm{Ca}^{2+}+2 \mathrm{HCO}_{3}^{-}
$$

The calculation was made according to the formula:

$$
\Delta r G(T)=\Delta r G^{\circ}(T)+R^{*} T * \lg k
$$

where $\mathrm{R}$ is the universal gas constant $\left(8.3143 \mathrm{~J} * \mathrm{deg}^{-1} * \mathrm{~mol}^{-1}\right)$;

$\mathbf{T}$ - the absolute temperature;

$\mathbf{k}$ - the equilibrium constant of the reaction (1):

$$
k=\frac{a_{\mathrm{Ca}^{2+}} \times a_{\mathrm{HCO}_{3}^{-}}^{2}}{a_{\mathrm{CO}_{2}}}
$$

in which $\mathbf{a}$ - the activity of the reaction components (1).

The calculation of $\Delta \mathrm{rG}^{\circ}(\mathrm{T})$ was made according to formulas 2.19-2.23 from [8] using the corresponding thermodynamic constants. The calculation was done for the two types of water: 1) stratal water, containing $8.83 \mathrm{mg} / \mathrm{L}$ of $\mathrm{Ca}^{2+}$ ions and $533.64 \mathrm{mg} / \mathrm{L}$ of $\mathrm{HCO}^{3-}$ ions; 2) river water injected to well and containing $100.00 \mathrm{mg} / \mathrm{L} \mathrm{Ca}^{2+}$ ions and $375.00 \mathrm{mg} / \mathrm{L}$ $\mathrm{HCO}^{3-}$ ions. The results of the calculations are presented in the table 2.

For clarity of the process, using obtained data the plots were drawn. Figure 1 shows the dependence of the Gibbs energy change of equation (1) depending on the temperature of stratal water and heated river water injected to well. Analysis of calculations and graphs shows the following. In the heating stratal groundwater of bitumen reservoir the carbonate 
equilibrium $(\Delta \mathrm{rG}(\mathrm{T})=0)$ is established at temperatures of about $+120^{\circ} \mathrm{C}$. Calcite dissolution of cement occurs below this temperature; above, on the contrary, calcite precipitates. In the injected hot river water into the reservoir, carbonate equilibrium is established at a temperature of $+90^{\circ} \mathrm{C}$. Calcite dissolves below this temperature and precipitates above.
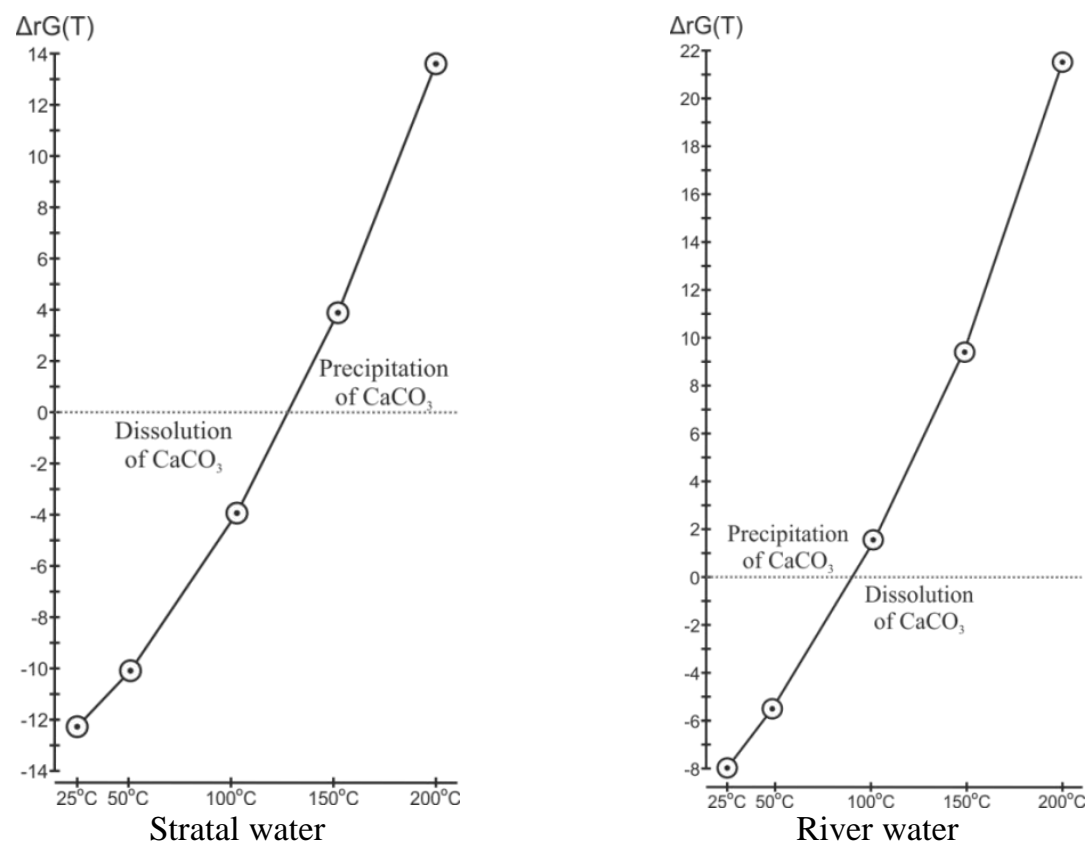

Fig. 1. Graphs of dependence of the Gibbs energy change depending on the temperature of stratal water and heated river water injected to well.

Table 2. Change of thermodynamic parameters $\left[\Delta \mathrm{fG}^{\circ}(\mathrm{T})\right]$ components, logarithm of equilibrium constant $\left(\operatorname{lgk}^{\circ}\right)$ and Gibbs energies $\left[\Delta \mathrm{rG}^{\circ}(\mathrm{T})\right.$ and $\left.\Delta \mathrm{rG}(\mathrm{T})\right]$ of reaction (1) at different temperatures for stratal and river waters.

\begin{tabular}{|c|c|c|c|c|c|c|c|c|c|}
\hline \multirow{2}{*}{$\begin{array}{c}\mathrm{T},{ }^{\circ} \\
\mathrm{C}\end{array}$} & \multicolumn{5}{|c|}{$\begin{array}{l}\text { Thermodynamic parameters of the reaction } \\
\text { component, }\left(\Delta f G^{\circ}(T)\right)\end{array}$} & \multirow{2}{*}{ 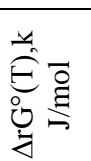 } & \multirow{2}{*}{$\operatorname{lgk}^{0}$} & \multicolumn{2}{|c|}{$\Delta \mathrm{rG}(\mathrm{T}), \mathrm{kJ} / \mathrm{mol}$} \\
\hline & $\mathrm{CaCO}_{3}$ & $\mathrm{H}_{2} \mathrm{O}$ & $\mathrm{CO}_{2}$ & $\mathrm{Ca}^{2+}$ & $\mathrm{HCO}_{3}^{-}$ & & & stratal & river \\
\hline 25 & $-1128,9$ & $-237,1$ & $-394,4$ & $-552,8$ & $-586,86$ & 33,83 & $-5,9$ & $-12,27$ & $-8,0$ \\
\hline 50 & $-1122,3$ & $-233,1$ & $-394,4$ & $-553,6$ & $-578,09$ & 39,97 & $-6,5$ & $-10,00$ & $-5,4$ \\
\hline 100 & $-1109,1$ & $-224,9$ & $-394,6$ & $-555,3$ & $-559,82$ & 53,63 & $-7,5$ & $-4,07$ & $+1,3$ \\
\hline 150 & $-1096,1$ & $-216,8$ & $-394,7$ & $-557,3$ & $-540,61$ & 69,07 & $-8,5$ & $+3,64$ & $+9,7$ \\
\hline 200 & $-1083,1$ & $-208,6$ & $-394,8$ & $-559,1$ & $-52,30$ & 86,81 & $-9,6$ & $+13,65$ & $+20,4$ \\
\hline
\end{tabular}

A question may arise whether calcite will dissolve simply by the action of water without the participation of carbon dioxide by the reaction:

$$
\mathrm{CaCO}_{3}+\mathrm{H}_{2} \mathrm{O}=\mathrm{Ca}^{2+}+\mathrm{HCO}_{3}^{-}+\mathrm{OH}^{-}
$$

since the initial components of this reaction are common for the system described by the carbonate equilibrium equation of reaction (1). We calculated the amounts of the Gibbs energy change $\Delta \mathrm{rG}^{\circ}(\mathrm{T})$ and amount of the logarithm of the equilibrium constant $\operatorname{lgk}^{\circ}$ of reaction (3) for temperatures of $25-200^{\circ} \mathrm{C}$. The results are shown in the table 3. 
Table 3. Thermodynamic parameters of $\Delta \mathrm{rG}^{\circ}(\mathrm{T})$ and $\operatorname{lgk}^{\circ}$ at various temperatures.

\begin{tabular}{|c|c|c|}
\hline $\mathrm{T},{ }^{\circ} \mathrm{C}$ & $\Delta \mathrm{rG}^{\circ}(\mathrm{T}), \mathrm{kJ} / \mathrm{mol}$ & $1 \mathrm{gk}^{\circ}$ \\
\hline 25 & $+69,06$ & $-12,10$ \\
\hline 50 & $+72,67$ & $-11,75$ \\
\hline 100 & $+81,34$ & $-11,36$ \\
\hline 150 & $+91,82$ & $-11,33$ \\
\hline 200 & $+104,65$ & $-11,55$ \\
\hline
\end{tabular}

These results show that the equilibrium constant of the reaction (3) is a million times less likely in comparison with reaction (1) and therefore it can be ignored.

\section{Conclusions}

Given the above, we can draw the following conclusions:

1. Depending on the mineral composition of water in the reservoir, when stationary conditions of develop are reached, it is necessary to maintain a temperature in the range from +90 to $+120^{\circ} \mathrm{C}$. In this case, a decrease in the bitumen viscosity will not be accompanied by processes of the "dissolution-precipitation" of calcites.

2. If it is necessary to improve the filtration-capacity properties of the reservoir, it is possible at the initial stages to maintain the temperature in the thermal chamber at the level of $+70-90^{\circ} \mathrm{C}$. This will lead to partial dissolution of calcite cement in sandstones.

3. To improve the technological characteristics of the reservoir layer and increase the recoverability of bitumen, it is recommended to inject hot water into the strata with low TDS.

This study was performed in the context of the Russian Government Program of Competitive Growth of Kazan Federal University

\section{References}

1. E. Korolev, S. Usmanov, D. Nikolaev, R. Gabdelvaliyeva, IOP Con. Series Earth and Env. Sci., 155(1) (2018)

2. R. Khisamov, V. Bazarevskaya, T. Tarasova, A. Kostina, R. Abusalimova, S. Panina, Neft. Khoz. - Oil Ind., 6 (2017)

3. E.A.Korolev, M.G. Khramchenkov, E.M. Khramchenkov, A.A. Eskin, R.R. Gabdelvalieva, A.N. Garaeva, Neft.Khoz. - Oil Ind., 1 (2018)

4. E. Korolev, A. Eskin, A. Kolchugin, V. Morozov, M. Khramchenkov, R. Gabdelvalieva, IOP Con. Series Earth and Env. Sci., 155(1) (2018)

5. B. Kurochkin, D. Baldenko, O. Rogachev, Neft.Khoz. - Oil Ind., 6 (2007)

6. T. Zakirov, A. Galeev, E. Korolev, I. Nuriev, E. Statsenko, Neft. Khoz. - Oil Ind., 8 (2015)

7. R. Ibragimov, E. Korolev, I. Minnegalirev, A. Lyamina, A. Eskin, 18th Int.Mult. Sci. GeoConf.SGEM 2018, 18(1.2) (2018)

8. M. Borisov, Yu. Shvarov, Thermodynamics of geochemical processes (Moscow: MSU Publishing House, 1992) 